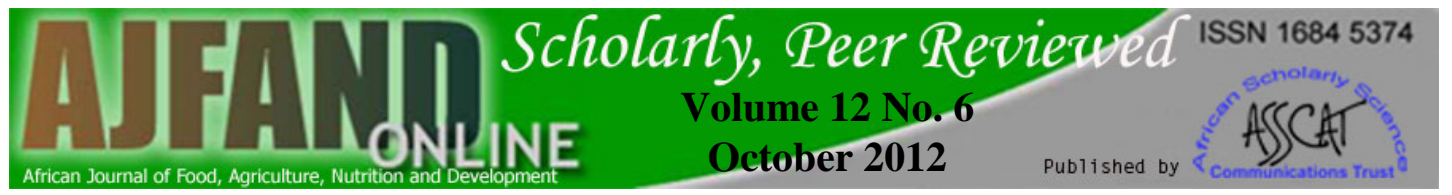

\title{
NATURAL ADDITIVES EFFECTS ON SOME QUALITY PARAMETERS OF UN-REFINED PEANUT OIL
}

\section{Akinoso $\mathbf{R}^{1 *}$ and IU Ekaette ${ }^{2}$}

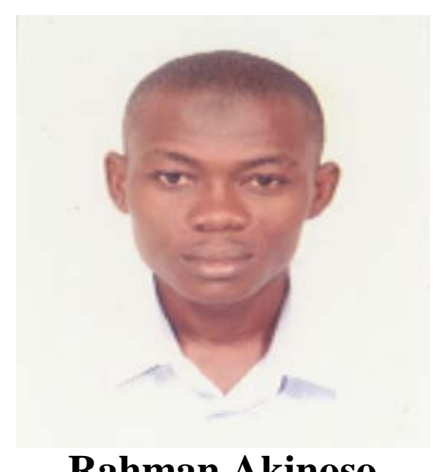

\section{Rahman Akinoso}

*Corresponding author email: akinoso2002@yahoo.com

${ }^{1}$ Department of Food Technology, Faculty of Technology, University of Ibadan, Ibadan Nigeria.

${ }^{2}$ Department of Food Engineering, Faculty of Engineering, University of Uyo, Nigeria.

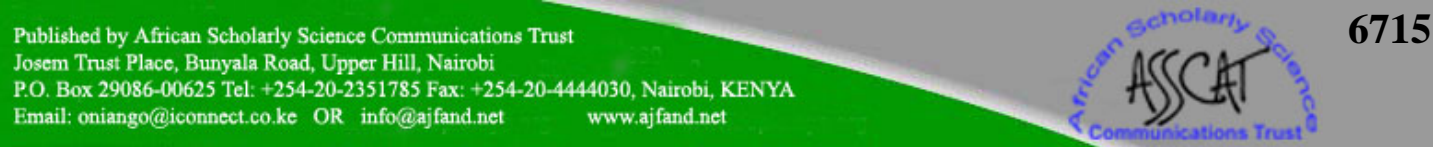




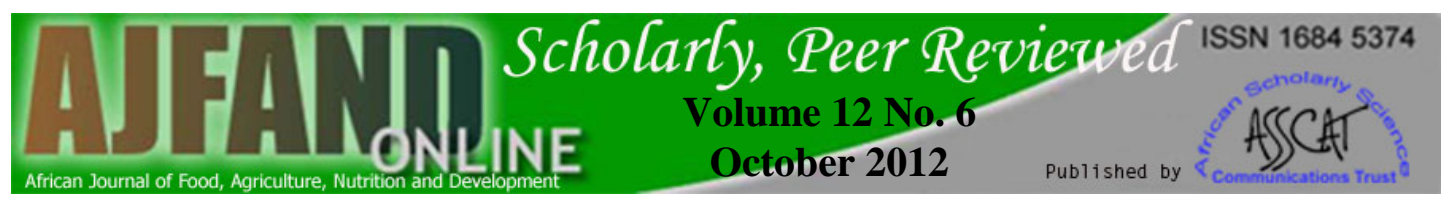

\section{ABSTRACT}

Edible oils are widely utilized in diets as a major source of fat and a heat transfer medium during frying. Improvement on nutritive value is a major concern in edible oil industry. Therefore, objectives of this work were to investigate the effects of sweet pepper (Capsicum annuum) and tomato fruit (Lycopersicon esculentum.) as additives on some physical and functional properties, nutritive values and stability of peanut (Arachis hypogaea) oil. Response surface methodology was employed to study effect of natural additives on peanut oil. The variables were additives ratio (5:0, 3:2, 2.5:2.5, 2:3, 0:5) of sweet pepper: tomato and incubation time (1, 1.5, 2.5, 4, $6 \mathrm{hrs})$. While the responses were oil iodine value, peroxide value, free fatty acid, saponification value, colour, viscosity, beta-carotene, vitamin $\mathrm{E}$ and vitamin $\mathrm{K}$. The calculated means for iodine value, peroxide value, free fatty acid, saponification value, colour, viscosity, $\beta$-carotene, vitamin $\mathrm{E}$ and vitamin $\mathrm{K}$ were $105.39 \pm 10.38$ Wijs, $9.89 \pm 2.81 \mathrm{mEqkg}^{-1}, 2.4 \pm 1.13 \%, 166.1 \pm 20.53$ $\mathrm{mgKOH} / \mathrm{g}, 0.16 \pm 0.2 \mathrm{~A}, 0.02 \pm 0.00 \mathrm{Nsm}^{-2}, 788.3 \pm 69.50 \mu \mathrm{g} / 100 \mathrm{~g}, 12.7 \pm 0.87 \mu \mathrm{g} / 100 \mathrm{~g}$ and $7.8 \pm 0.59 \mu \mathrm{g} / 100 \mathrm{~g}$, respectively. Coefficient of determination $\left(\mathrm{R}^{2}\right)$ of models for iodine value, peroxide value, free fatty acid, colour, viscosity, $\beta$-carotene and vitamin $\mathrm{E}$ were $0.76,0.91,0.76,0.89,0.93,0.97$ and 0.84 , respectively. Functional properties of the oil including iodine value and saponification value reacted differently to treatment. Iodine value was significantly $(\mathrm{p}<0.05)$ influenced while non-significant $(\mathrm{p}>0.05)$ effect was recorded for the saponification value. The treatments significantly $(p<0.05)$ influence peroxide value and free fatty acid of the extracted oil. Physical properties of the peanut oil measured by colour and viscosity were significantly influenced by the treatment $(p<0.05)$. Nutritive values of the peanut oil which were beta-carotene and Vitamin $\mathrm{E}$ were significantly $(\mathrm{p}<0.05)$ influenced by the treatments but Vitamin K was not significantly influenced.

Key words: Peanut, Additives, Oil, Stability, Properties 


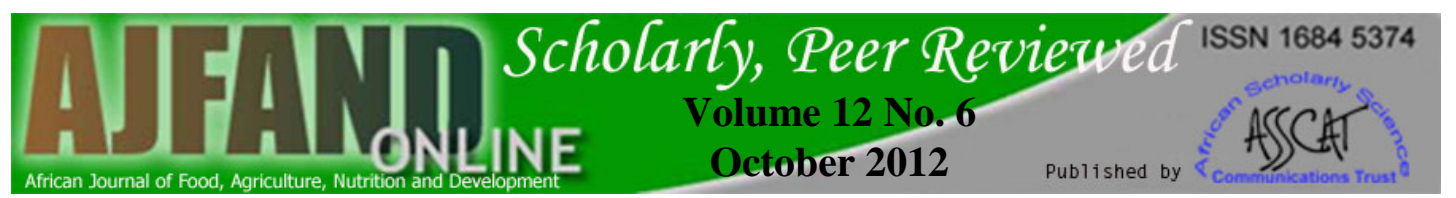

\section{INTRODUCTION}

Peanut (Arachis hypogaea) is a leguminous plant grown mainly for its seeds. It is the thirteenth most important food crop and fourth most important source of vegetable protein in the world [1]. The major peanut producers in the world are China, India, Nigeria, and Sudan [2]. Peanut is a concentrated source of energy with its seeds having nutritive values of fat (41-52\%), easily digestible protein (21-30\%), and carbohydrate $(11-27 \%)$ [3]. The seed is valued for its high oil content [4]. The oil extracted from peanut is useful in the manufacture of margarine, mayonnaise, salad oils, soaps and lather shaving creams [5].

Fortification of edible oil to reduce deficiency of vitamin A is recommended [6]. Synthesized additives are commonly used to fortify edible oil. The availability and increased consumption of beta-carotene-rich foods in the daily diet is a preferred strategy for improving nutritional status than synthetic vitamin A dosage approaches [5]. Vegetables are highly nutritious sources of vitamins and small amounts of minerals [7]. Sweet pepper (Capsicum annuum) and tomato fruit (Lycopersicon esculentum.) are vegetables widely cultivated in Nigeria. Sweet pepper it's known for its pungency, impartation of flavours to foods and richness in vitamins. Sweet pepper and Tomato being rich in carotenoids also will impart colour and increase the $\beta$-carotene content of the oil. In human medicine, $\beta$-carotene not only serves as valuable source of vitamin $A$, but also serves as a potent antioxidant, scavenging free radicals and quenching singlet oxygen; thereby it is capable of reducing the risk of development of certain types of cancer [8].

Improvement on nutritive value is a major concern in edible oil industry. Therefore, objectives of this work were to study the effects of sweet pepper and tomato fruit as additives on some physical and functional properties, nutritive value, and stability of peanut oil.

\section{MATERIALS AND METHODS}

\section{Experimental design}

The experimental design was based on the rotatable design of Response Surface Methodology for a two-variable case as described by Montgomery [9]. The two independent variables were the additives ratio (A) and incubation time (B). The combinations of the additives were 100:0, 60:40, 50:50, 40:60 and 0:100 corresponding to $5 \mathrm{~g}$ of sweet pepper/0g of tomato, $3 \mathrm{~g}$ of sweet pepper/2g of tomato, $2.5 \mathrm{~g}$ of sweet pepper/2.5g of tomato, $2 \mathrm{~g}$ of sweet pepper/3g of tomato, and $0 \mathrm{~g}$ of sweet pepper $/ 5 \mathrm{~g}$ of tomato. The incubation time ranged from 1 to 6 hrs. The $\mathrm{pH}$ of the mixture was unmodified and the temperature of incubation was kept constant at $40 \pm 2{ }^{\circ} \mathrm{C}$ for all the treatments. Total numbers of treatments were 13 (Table 1). All the experimental procedures were replicated three times; mean values were recorded. 


\section{Preparation of samples}

Cultivars of sweet pepper, tomato and peanut used for the experiment were $O A B$ 99-7, Roma-VF and Boro light respectively. The raw materials (sweet pepper, tomato fruits and peanut) were obtained from National Horticultural Research Institute, Ibadan, Nigeria. They were cleaned and ground using plate mill (model FE 145A, FOBA Engineering, Nigeria) separately. Their initial moisture contents were determined using ASABE [10], while sweet pepper and tomato $\mathrm{pH}$ determination were carried out as described using the glass electrode TOA pH meter [11]. Sweet pepper-tomato ratio (5 g) was prepared as additive. This mixture was added to $20 \mathrm{~g}$ of peanut and incubated at $40 \pm$ $2{ }^{\circ} \mathrm{C}$ at varied time (Table 1) using a Gallenkamp (size two) incubator. Oil was extracted from incubated samples using Soxhlet apparatus using gravimetric method for crude fat determination [12]. Oil from un-treated sample of same oilseed was used as control.

\section{Determination of some physicochemical properties of raw materials}

The physicochemical properties of sweet pepper, tomato and peanut were determined to establish their quality characteristics. These were determined using recommended analytical and sampling methods, Codex Stan 234-1999 as guide [13]. Methodologies adopted were AOAC method for apparent density for specific gravity [12]; ASABE S410.1 method for moisture content [10]; AOAC 981.12 method for pH; AOAC 920.39C method for fat; AOAC 942.15 method for titratable acidity; AOAC 950.49 method for ash; AOAC 962.10 method for fiber; AOAC 954.01 for crude protein determination [12] and carbohydrate by calculation as reported [14]. Unit mass was measured by electronic weigh balance of 0.01g accuracy (JD-3G Series, Shenyang Longteng Electronic Co. Ltd, Liaoning, China). The colour of the additives was determined with the aid of spectrophotometer (UVIKON XL, North Star Scientific, Leeds, UK) at $470 \mathrm{~nm}$ absorbance.

\section{Determination of iodine value}

The iodine value was determined using AOCS Method Cd 1-25 [15]. The procedure involved adding excess Wijs reagent to the oil sample and allowing the mixture to react for $30 \mathrm{~min}$ at $25 \pm 5{ }^{\circ} \mathrm{C}$. Excess reagent was treated with potassium iodide to convert it to equivalent iodine and titrating with thiosulfate reagent and a starch indicator until blue color disappears.

\section{Determination of peroxide value}

The peroxide value of the oil was determined by a modified American Oil Chemists' Society standard method Cd 8-53 [15]. Five milliliters of oil was placed on a test paper (United States Patent 4098575). Ten milliliters of water was added to oil soaked paper. The intensity of the blue colour developed on the test paper is proportional to the peroxide value of the oil. Colour of the paper was compared to a predetermined standard [16]. 


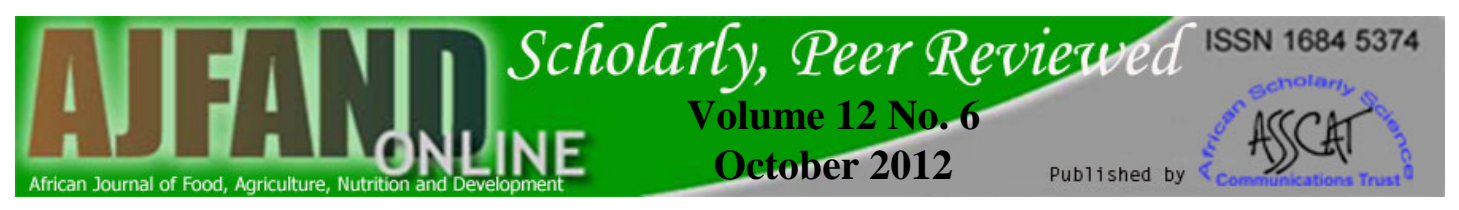

\section{Determination of free fatty acid content (FFA)}

Free fatty acid (FFA) was calculated using AOCS method Ca5a - 40 [15]. Mixture of $1.0 \mathrm{~g}$ of oil, $25 \mathrm{ml}$ of diethyl ether, $25 \mathrm{ml}$ of ethanol? and $1 \mathrm{ml}$ of phenolphthalein solution was prepared. The mixture was titrated with aqueous $0.5 \mathrm{~N} \mathrm{NaOH}$, which was shaken vigorously until a permanent faint pink colour appeared and persisted for $15 \mathrm{sec}$. The percentage of FFA in the sample was calculated using the equation1 below.

$$
\% \text { FFA }=\frac{\text { Titration }(\mathrm{ml}) \times 0.141 \times 100}{\text { Wt of sample used }} \ldots \ldots \ldots \ldots \ldots 1
$$

\section{Determination of saponification value (SV)}

Saponification value of oil sample was determined according to the method reported by Pearson [17]. This was done by dissolving $1 \mathrm{~g}$ of the oil in $12.5 \mathrm{ml}$ of $0.5 \%$ ethanolic $\mathrm{KOH}$. One milliliter of phenolphthalein was added to the mixture as indicator before titration with $0.5 \mathrm{~N}$ HCL. A blank determination was also carried out under the same condition. Saponification value was calculated using equation 2 below.

$$
\mathrm{SV}=56.1 \mathrm{~N} \frac{(\mathrm{Q}-\mathrm{Z})}{\mathrm{W}} \ldots \ldots \ldots \ldots \ldots . \ldots . \ldots . . . . . . .2
$$

Where $\mathrm{N}$ is normality of HCL; $Q$ is volume $(\mathrm{ml})$ of $\mathrm{H}_{2} \mathrm{SO}_{4}$ for blank (ml); $Z$ is volume (ml) of $\mathrm{H}_{2} \mathrm{SO}_{4}$ for sample (ml); $\mathrm{W}$ is Weight of oil (g) and 56.1 is constant which is equivalent to weight of potassium hydroxide.

\section{Determination of colour}

The color of the oil was determined using spectrophotometer colour method AOCS method Cc 13c -50 [15]. Mixture of oil and n-hexane was prepared in ratio 1 to $9 \mathrm{ml}$ and the absorbance was read at $470 \mathrm{~nm}$ on UVIKON XL spectrophotometers (North Star Scientific, Leeds, UK).

\section{Determination of oil viscosity}

The oil viscosity was evaluated as described [18]. It was determined at $25{ }^{\circ} \mathrm{C}$ using Brookfield Synchrolectric Viscometer (Model RVT, Rookfield Engineering Laboratories, Stoughton, MA) and a helipath stand equipped with a T - B spindle operated at $2.5 \mathrm{rpm}$.

\section{Determination of beta-carotene ( $\beta$-carotene)}

Beta-carotene was determined according to AOAC method No 970.64 [12]. A mixture of $2 \mathrm{~g}$ of oil sample, $10 \mathrm{ml}$ of distilled water and $25 \mathrm{ml}$ alcoholic $\mathrm{KOH}$ solution was heated in boiling water bath (Techmel and Tecmel, Texas, USA) for 1 hour. The mixture was cooled to room temperature $\left(29^{\circ} \mathrm{C}\right)$, after which $30 \mathrm{ml}$ of water was added. After hydroxylation, the mixture was extracted using chloroform. Traces of water in the extract was removed by the addition of $2 \mathrm{~g}$ anhydrous $\mathrm{Na}_{2} \mathrm{SO}_{4}$. Standard solution of $\beta$-carotene 
was obtained by dissolving $0.003 \mathrm{~g}$ of $\beta$-carotene in $100 \mathrm{ml}$ of chloroform. Thereafter, a series of standard solutions of different concentration were obtained and their absorbance determined. Absorbance of sample and standards were read on the spectrophotometer at $470 \mathrm{~nm}$ wavelength (UVIKON XL spectrophotometers, North Star Scientific, Leeds, $\mathrm{UK})$. Values of $\beta$-carotene were calculated using equation 3 below:

$\beta-$ carotene $\left(\frac{\mu \mathrm{g}}{100 \mathrm{~g}}\right)=\frac{\text { absorbance of sample } X \text { dilution factor X gradient }}{\text { weight of sample }} \ldots \ldots . . . .3$

\section{Determination of Vitamin $\mathbf{E}$}

Vitamin E was determined using AOAC 971.30 method [12]. A mixture of oil (1g), absolute alcohol $(10 \mathrm{ml})$ and $1 \mathrm{M}$ alcoholic sulphuric acid $(20 \mathrm{ml})$ was refluxed for 45 minutes in a condenser and cooled for 15 minutes. Unsaponifiable matter in the mixture was extracted with dimethyl ether. The extracts evaporated at a low temperature and the residues obtained were dissolved in $10 \mathrm{ml}$ absolute alcohol. Absolute alcohol (5 ml) and $1 \mathrm{ml}$ conc. $\mathrm{HNO}_{3}$ was added to aliquots of the sample and standards (0.3-3.0 mg vitamin E). The mixture was evaporated in a water bath (Techmel and Tecmel, Texas, USA) at $90^{\circ} \mathrm{C}$ for 3 minutes from the time the alcohol started boiling. A series of standard solutions of known concentrations were determined with reference to their absorbance from which average was recorded. It absorbance was measured at $290 \mathrm{~nm}$ using a UVIKON XL spectrophotometer (North Star Scientific, Leeds, UK) against a blank containing $5 \mathrm{ml}$ absolute alcohol and $1 \mathrm{ml}$ conc. $\mathrm{HNO}_{3}$ and treated in a similar manner. Equation 4 was applied to determine Vitamin E.

Vitamin $\mathrm{E}\left(\frac{\mu \mathrm{g}}{100 \mathrm{~g}}\right)=\frac{\text { absorbance of sample X dilution factor X gradient }}{\text { weight of sample }} \ldots \ldots \ldots 4$

\section{Determination of vitamin $\mathrm{K}$}

Vitamin K was determined using AOAC method 992.27 [12]. Five grams of oil sample was weighed into a $250 \mathrm{ml}$ beaker and $30 \mathrm{ml}$ of butyl alcohol was added. Magnetic stirrer was used to homogenise the solution. The resulting mixture was filtered through a Whatman No 42 filter paper. Three drops of 2, 4-dinitrophenyl hydrazine and $3 \mathrm{ml}$ of alcoholic ammonia were added to $10 \mathrm{ml}$ of the mix. Standard solutions of vitamin $\mathrm{K}$ from $0-20 \mu \mathrm{g} / \mathrm{ml}$ were prepared and treated as samples to obtain the slope of the standard curve. The absorbance of standards and sample were read using UVIKON XL spectrophotometers (North Star Scientific, Leeds, UK) at $325 \mathrm{~nm}$ wavelength. Vitamin K in $\mu \mathrm{g} / 100 \mathrm{~g}$ was calculated using equation 5 .

Vitamin $\mathrm{K}\left(\frac{\mu \mathrm{g}}{100 \mathrm{~g}}\right)=\frac{\text { absorbance of sample } \mathrm{X} \text { dilution factor } \mathrm{X} \text { gradient }}{\text { weight of sample }} \ldots \ldots . . . .5$ 


\section{Data analysis}

Mean values of three replicates recorded as obtained data were analyzed using Analysis of Variance (ANOVA) and regression. Test of significance was fixed at 95\% confidence level. Second-order polynomial equations were developed to express the relationship between variables and responses using proprietary software (Design-Expert, Statese Inc., Minneapolis, USA).

\section{RESULTS}

\section{Preliminary data}

The physical and chemical properties of sweet pepper, tomato and peanut used for the experiment were presented as Table 2.

\section{Iodine value}

The obtained iodine values (IV) ranged from 100.07 to 116.9 Wijs (Table 3). Least value is slightly lower than control value of 103.38 Wijs. Analysis of variance of the data showed significant effect of treatments $(p<0.05)$ on iodine value of the oil. A second order model 2FI (Equation 6) was adequate to describe the variation in the iodine value of the peanut oil due to additive ratio (A) and incubation time (B). Additives ratio (A) and interaction between the responses were the significant model terms at $p<0.05$. Visual illustration of the relationship is shown as Fig. 1. A curve linear trend was observed with additives showing higher effect on the response.

\section{$\mathrm{IV}=+77.13+16.91 \mathrm{~A}-7.93 \mathrm{~B}-15.86 \mathrm{AB} \ldots \ldots \ldots . . .6$}

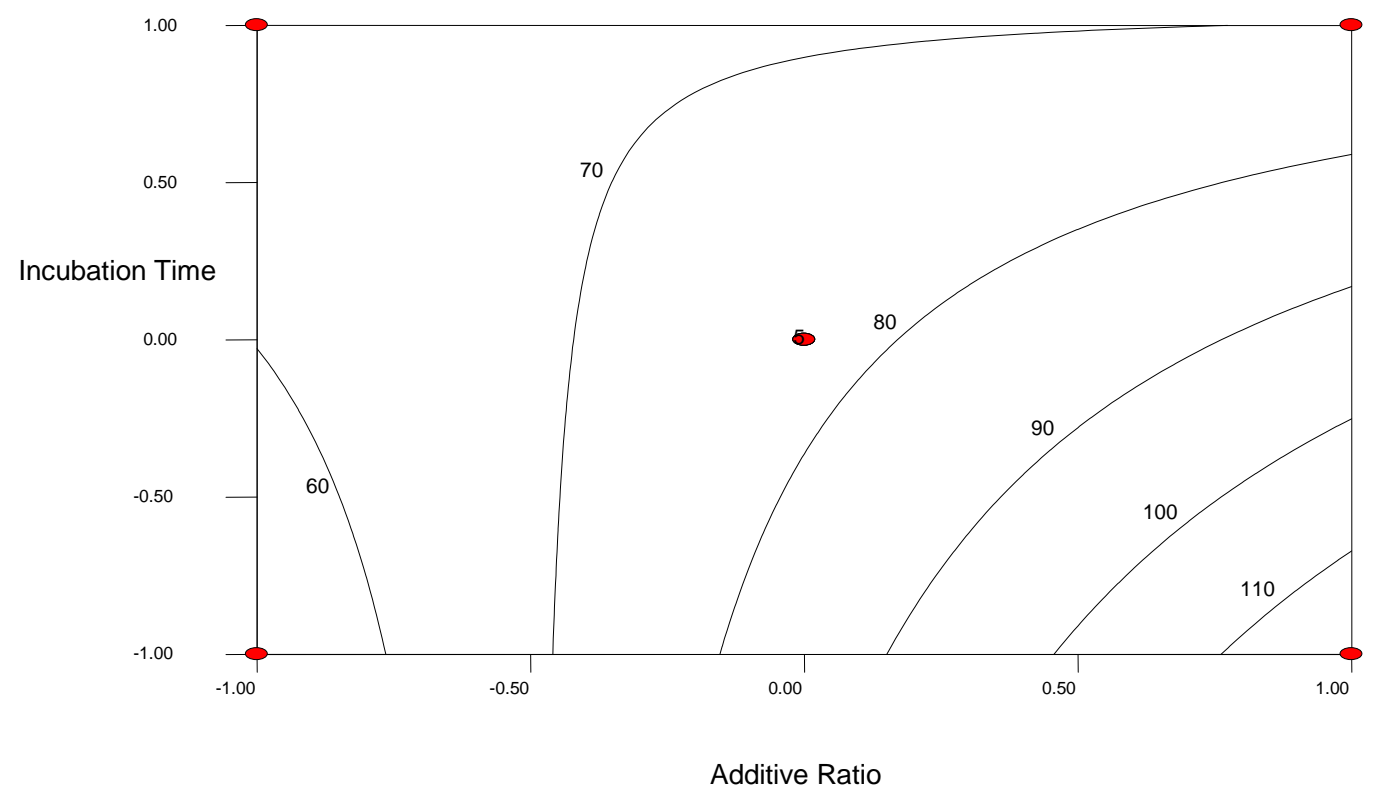

Figure 1: Contour plot of treatments effect on iodine value of oil 


\section{Peroxide value}

Minimum and maximum peroxide values (PV) were 5.4 and 12.3 meqkg ${ }^{-1}$, respectively (Table 3). Least peroxide value recorded from the experiment was higher than the control $\left(3.6\right.$ meqkg $\left.^{-1}\right)$. Treatments significantly influenced $(\mathrm{p}<0.05)$ the peroxide value of the oil. Response surface cubic model was appropriate to illustrate the relationship (Equation 7). The contour plot of the relationship showed asymmetric shape (Fig. 2). Coefficient of the determination $R^{2}$ of the model was high 0.91 .

$$
P V=10.70+1.5 A+1.2 B-2.2 A B-1.1 A^{2}+0.6 B^{2}-3.5 A^{2} B+0.8 A B^{2} \ldots \ldots 7
$$

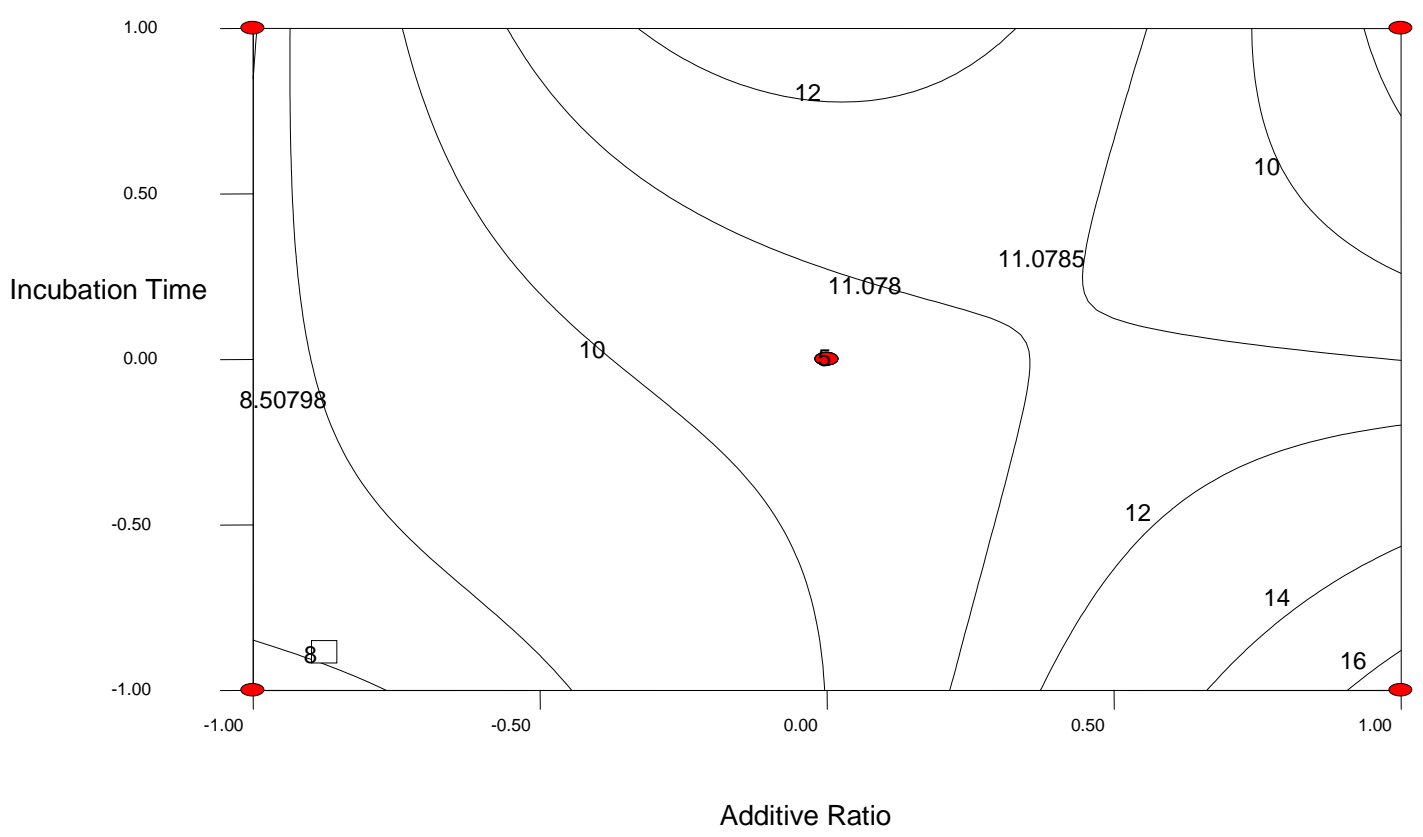

Figure 2: Contour plot of treatments effect on peroxide value of oil

\section{Free fatty acid}

Treatment of the oil by addition of tomato and pepper significantly ( $<<0.05)$ affects its free fatty acid content (FFA). Obtained FFA ranged from 0.84 to $4.82 \%$ (Table 3). Minimum value was higher than $0.56 \%$ of untreated peanut oil used as control. Regression analysis results also revealed that linear and quadratic terms ( $A$ and $A^{2}$ ) of the additives were significant model terms at $\mathrm{p}<0.05$ (Equation 8). Figure 3 , visually illustrates the interaction between additives, incubation time and free fatty acid content of the oil. Trend of the plot showed increase in free fatty acid with increase incubation time.

FFA $=+3.14+0.63 \mathrm{~A}-0.32 \mathrm{~B}-0.85 \mathrm{AB}-0.69 \mathrm{~A}^{2}-0.54 \mathrm{~B}^{2} \ldots \ldots \ldots . . . .8$ 

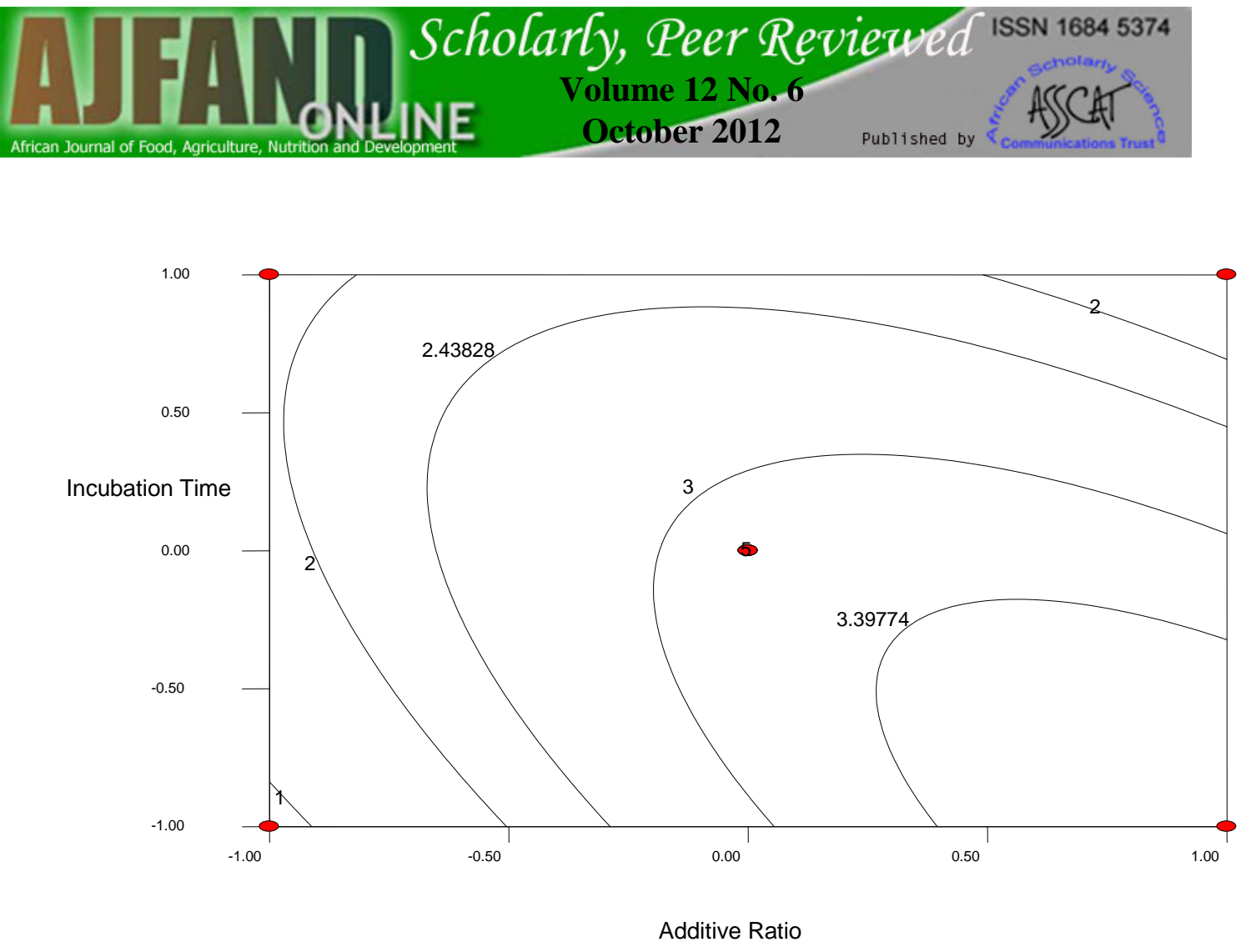

Figure 3: Contour plot of treatments effect on free fatty acid of oil

\section{Saponification value}

The mean saponification value (SV) of the oil was $166.14 \pm 20.55 \mathrm{mg} / 100 \mathrm{~g}$. The contour plot (Fig. 4) demonstrates that linear relationship exists between the response and the variable. However, non significant effect $(\mathrm{p}>0.05)$ of treatments on SV was observed. Generated regression model was not fit. 

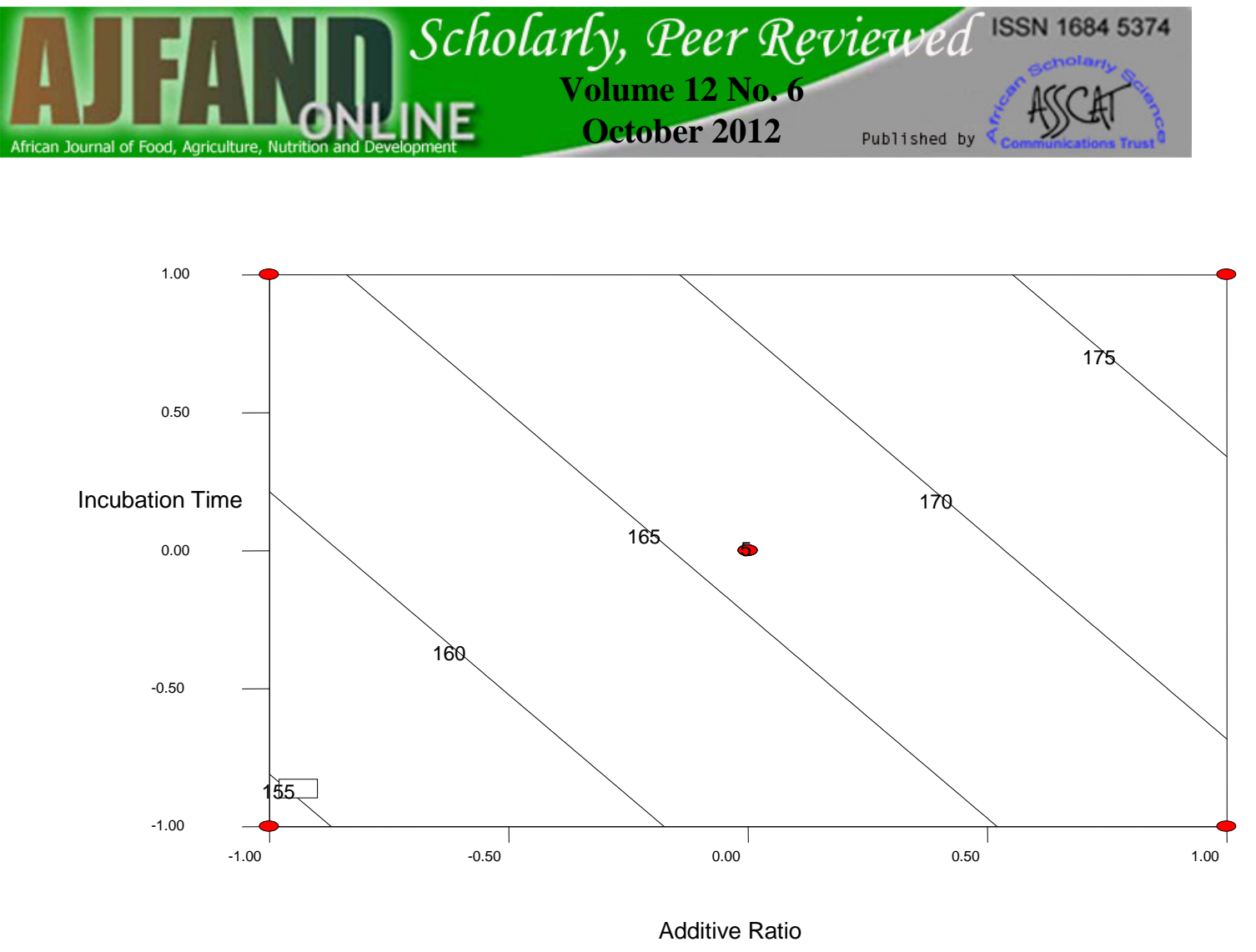

Figure 4: Contour plot of treatment effect on saponification value of oil

\section{Colour}

The colour (CL) readings ranged from 0.13 to 0.20 A (Table 3). It was observed that treatments with high incubation time produced high colour concentration. Effect of treatment was significant $(\mathrm{p}<0.05)$ on oil colour. Both additives and incubation time were significant terms of the regression model (Equation 9). Figure 5 showed the contour plot of the interaction between treatment and oil colour. The plot revealed parabolic shape.

$\mathrm{CL}=+14.4-1.42 \mathrm{~A}+0.91 \mathrm{~B}+0.33 \mathrm{AB}+1.24 \mathrm{~A}^{2}+2.09 \mathrm{~B}^{2}$ .9 

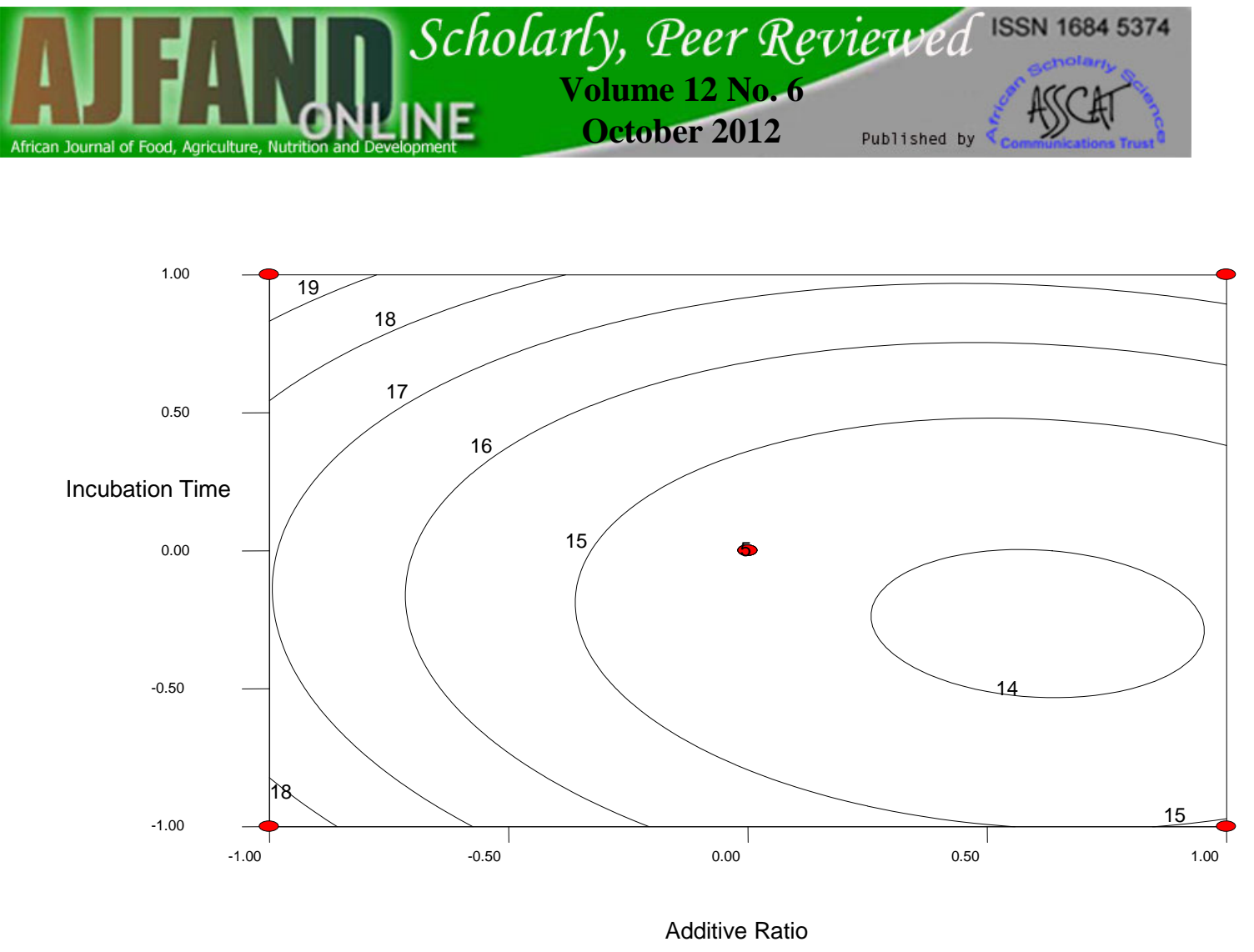

Figure 5: Contour plot of treatments effect colour of oil

\section{Oil viscosity}

Minimum and maximum viscosities (Vs) of treated oil were 0.01 and $0.02 \mathrm{Nsm}^{-2}$ respectively, whereas that of the control was $0.01 \mathrm{Nsm}^{-2}$ (Table 3). Effect of additives and incubation time were significant $(\mathrm{p}<0.05)$ on oil viscocity. The contour plot (Fig. 6) revealed pronounced independent influence of the variables on the oil viscosity. Equation 10 , mathematically expresses the relationship. Coefficient of the determination $R^{2}$ of the model was high 0.93 .

$\mathrm{Vs}=1.5-0.2 \mathrm{~A}+0.09 \mathrm{~B}-0.11 \mathrm{AB}+0.18 \mathrm{~A}^{2}+0.12 \mathrm{~B}^{2}-0.18 \mathrm{~A}^{2} \mathrm{~B}+0.40 \mathrm{AB}^{2} \ldots \ldots 10$ 

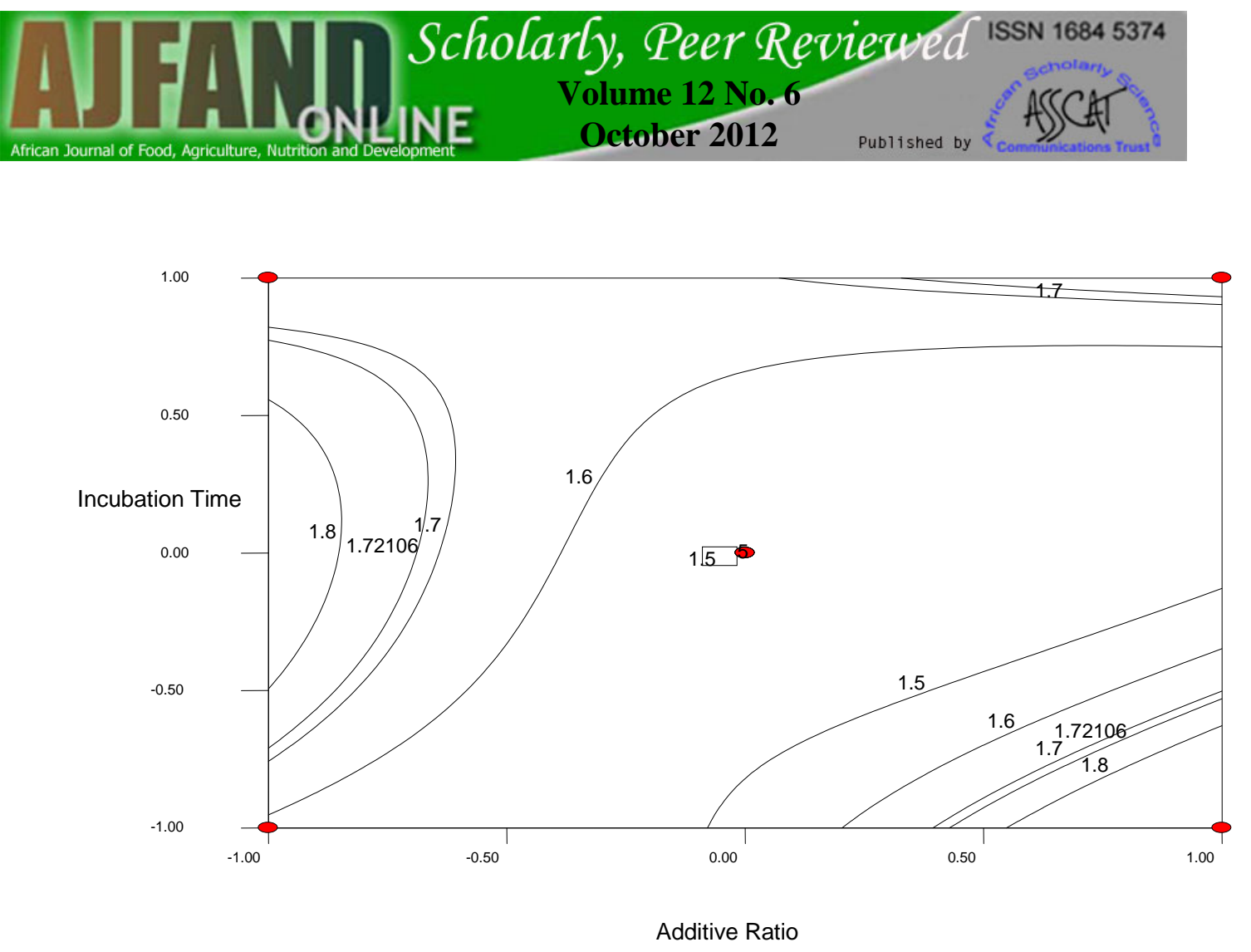

Figure 6: Contour plot of treatments effect on viscosity of oil

\section{Beta-carotene ( $\beta$-carotene)}

Average beta-carotene of the treated oil was $788.3 \pm 69.5 \mu \mathrm{g} / 100 \mathrm{~g}$. Least beta carotene recorded from the treated samples was $670 \mu \mathrm{g} / 100 \mathrm{~g}$ while $866 \mu \mathrm{g} / 100 \mathrm{~g}$ was the highest value (Table 3). Difference in control $(525 \mu \mathrm{g} / 100 \mathrm{~g})$ and least value was $165 \mu \mathrm{g} / 100 \mathrm{~g}$ (31.4\%). Analysis of variance showed significant effect of treatments at $\mathrm{p}<0.05$ on betacarotene. Response surface quadratic model (Equation 11) generated to predict the relationship revealed higher effect of additives (A) than incubation time (B). Coefficient of determination of the model was 0.94 . Contour plot of the relationship is shown as Figure 7.

$\beta-$ carotene $=866-17.61 \mathrm{~A}+3.30 \mathrm{~B}+18.5 \mathrm{AB}-48.38 \mathrm{~A}^{2}-77.89 \mathrm{~B}^{2}$ 

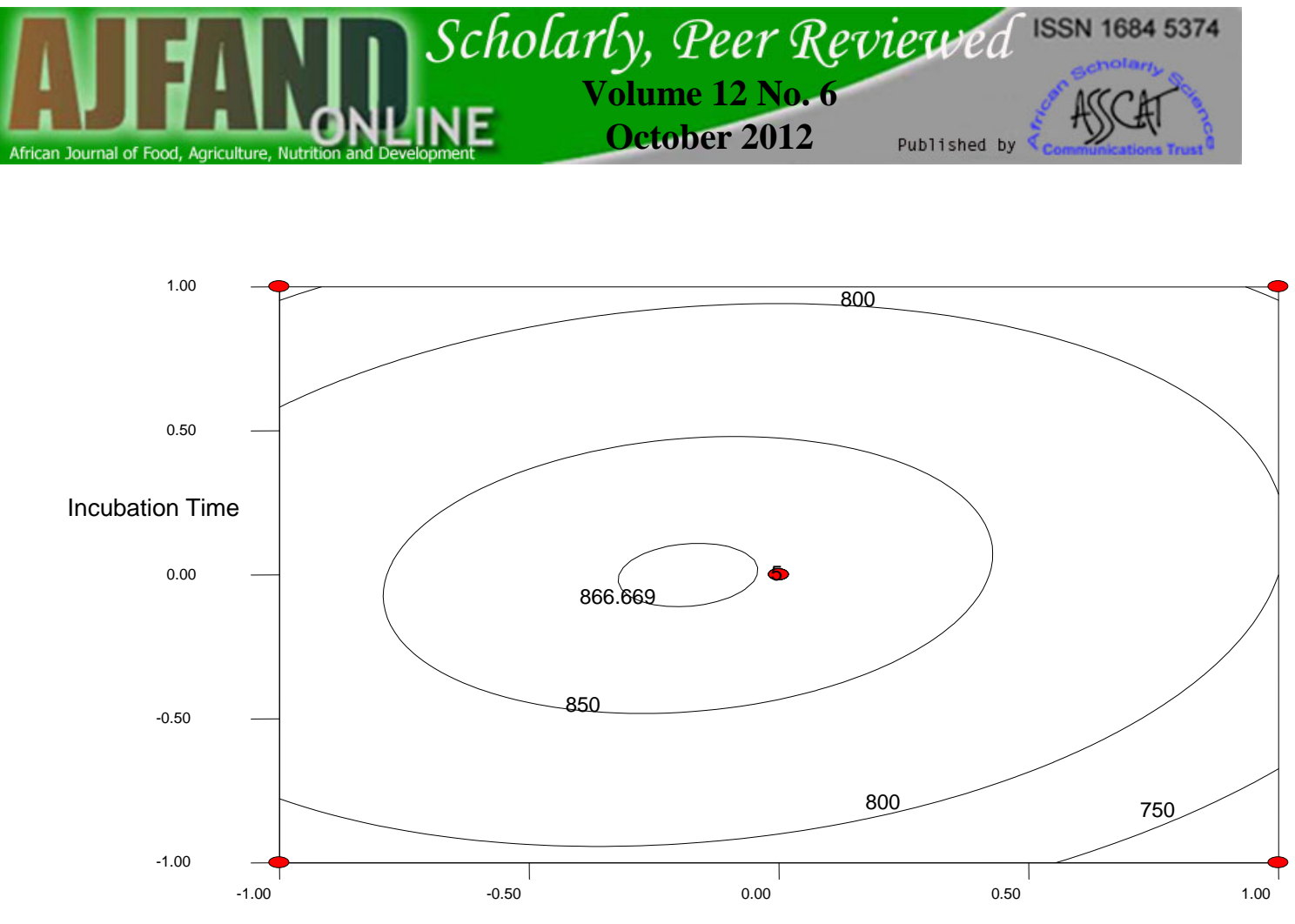

Additive Ratio

Figure 7: Contour plot of treatments effect on beta-carotene of oil

\section{Vitamin E}

The treatments significantly $(\mathrm{p}<0.05)$ increased vitamin $\mathrm{E}$ (Vit E) content of the oil. About 50\% increment was recorded between least and control values. From the contour plot (Fig. 8) and regression model (Equation 12) effect of incubation time (B) was more pronounced.

Vit $\mathrm{E}=12-0.34 \mathrm{~A}+0.53 \mathrm{~B}+0.1 \mathrm{AB}+0.73 \mathrm{~A}^{2}+0.41 \mathrm{~B}^{2} \ldots \ldots \ldots . .12$ 

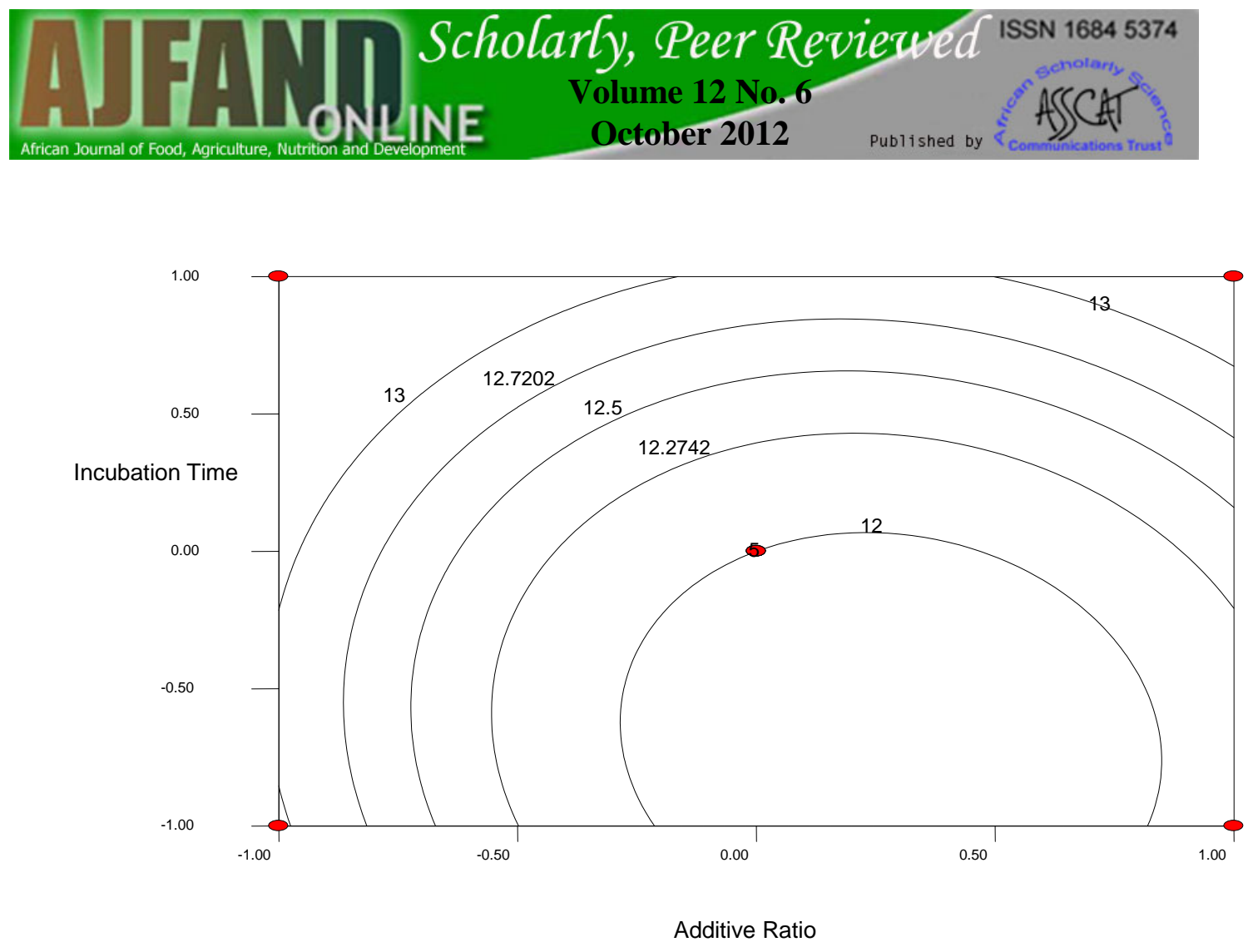

Figure 8: Contour plots of treatments effect on Vitamin E of oil

\section{Vitamin K}

Recorded Vitamin K (Vit K) ranged from 6.75 to $8.61 \mu \mathrm{g} / 100 \mathrm{~g}$ with mean value of $7.75 \pm$ $0.058 \mu \mathrm{g} / 100 \mathrm{~g}$. The treatments had no significant effect $(\mathrm{p}>0.05)$ on the Vitamin $\mathrm{K}$ content of the extracted oil. Attempt to use model equation to predict the relationship also showed poor fitness. The model did not satisfy lack of fit test.

\section{DISCUSSION}

\section{Preliminary data}

Fruits are graded by their physical characteristics (size, weight, colour and shape), internal attributes (soluble solids content, moisture content) and rating quality (proximate composition) [19]. Based on these quality parameters, pepper and tomato used for the study can be classified as matured-ripe fruits [20]. The general specification project for pickled products established by the processed fruit and vegetable committee of the Codex Alimentarius Commission FAO/OMS, recommend a maximum $\mathrm{pH}$ specification of 4.6 for pickled products [21]. The $\mathrm{pH}$ of the peanut and tomato fruit were in agreement with reported natural values for the crops [4, 7]. The information is required because enzymatic activities are $\mathrm{pH}$ dependent.

\section{Iodine value}

Iodine value is a measure of reactive groups like the double bound in the mixture. Natural enzymes that are present in tomato fruit might have acted as catalyst for the reaction [22]. 


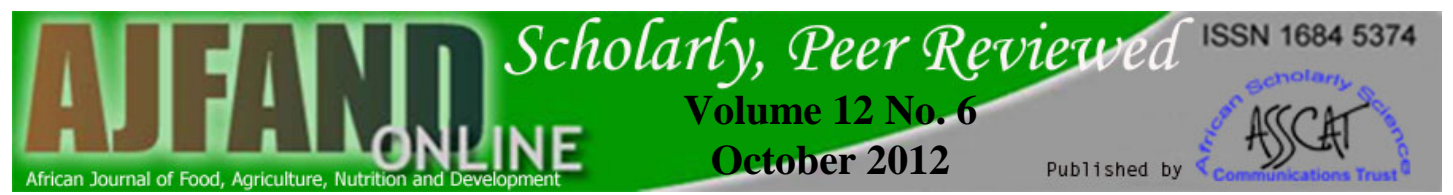

Similar observation was reported on iodine value of olive fruit oil treated with pectinase, an enzyme [23]. Increase in iodine value denotes increase in the degree of un-saturation of the oil [24]. Coefficient of determination $R^{2}$ of the model was 0.76 which showed that model can only explain $76.18 \%$ variability in the response.

\section{Peroxide value}

This observed trend of peroxide values in this study was contrary to reports that enzymatic treatments reduced peroxide value of some other vegetable oils [23, 25]. Peroxides are among the oxidation products formed when the double bonds of unsaturated fats become oxidised and an increase in peroxide value could have been caused by the peroxidase activity present in tomato and pepper reference. Peroxide value is used as indicator of deterioration of oils. Recommended maximum peroxide value in edible oil is $10 \mathrm{meq} \mathrm{kg}{ }^{-1}$ [6]. High PV of the extracted oil may be traced to high moisture contents of pepper and tomato. Moisture content naturally accelerates rate of oxidative reaction [26]. High coefficient of determination $\left(\mathrm{R}^{2}\right)$ of the model 0.91 is an indication of model fitness. The irregular shape of the contour plot (Fig. 2) may justify why the cubic quadratic response model was appropriate.

\section{Free fatty acid}

Other authors reported an increase in free fatty acid of olive oil as result of addition of enzymes [25]. Thus, natural enzymes in pepper and tomato might have caused the observed FFA rise in the treated peanut oil. Free fatty acid content is one of the major quality parameters of edible oils. Permissible level of free fatty acid in un-refined vegetable oil is $2 \%$ [6].

\section{Saponification value}

Saponification values of domestic vegetable oils range from 180 to $200 \mathrm{mgKOH} / \mathrm{g}$ [27]. The higher the saponification number, the higher the number of fatty acids of low molecular weight. It is obvious from the contour plot (Fig. 4) that a linear relationship exists between the response and the variable. That is rate of change of saponification value is directly proportional combined effect of additive ratio and incubation time.

\section{Colour}

The observation that treatments with high incubation time produced high colour concentration is suggesting that incubation encourages colour formation reaction. The red colour of pepper and tomato is due to carotenoids [25]. The presence of appreciable quantity of carotenoids, a colour pigment in sweet pepper and tomato might have caused the noticeable difference in appearance. The parabolic shape of Fig. 5 is an indication that the saddle point was not centered. 


\section{Oil viscosity}

Dependence of oil viscosity on treatment may be traced to the mixture of additives (sweet pepper \& tomato) which possess high viscosity. High coefficient of determination $R^{2}$ (0.93), is an indication that the model can be used to navigate the design space.

\section{Beta-carotene}

Coefficient of determination of the model was 0.94. This suggests good fitness. $\beta$ carotene accounts for more than $90 \%$ of total carotenoids in vegetables [28]. Noticeable difference between treated and un-treated oil beta-carotene may be traced to migration of beta-carotene from the additives (tomato \& sweet pepper) to the peanut during incubation. Symmetric shape of Fig. 7 is an indication of consistency.

\section{Vitamin E}

Vitamin $\mathrm{E}$ is a fat-soluble vitamin naturally occurring in peanuts with $\alpha$-tocopherol on the greater side compared to other tocopherols [29]. Significant effect of pepper and tomato mixture on vitamin E content be associated with enzymatic reaction during the incubation period.

\section{Vitamin K}

Vitamin $\mathrm{K}$ is not originally present in peanut and its occurrence in vegetables is low [29]. This may account for the obtained result.

\section{CONCLUSION}

The extraction of peanut oil with the use of sweet pepper and tomato fruit as additives in a controlled environment at $40 \pm 2^{\circ} \mathrm{C}$ revealed that functional properties of the oil, namely, iodine value and saponification value reacted differently to treatment. Iodine value was significantly influenced while no significant effect was recorded for the saponification value. Tests of rancidity of the oil showed that peroxide value and free fatty acid were significantly influenced by the treatments. Physical properties of the peanut oil measured by colour and viscosity were significantly influenced by the treatment. Nutritive values of the peanut oil viz beta-carotene and Vitamin E were significantly influenced by the treatments but Vitamin K was not significantly influenced. This information is of benefit to peanut oil producers and consumers. 


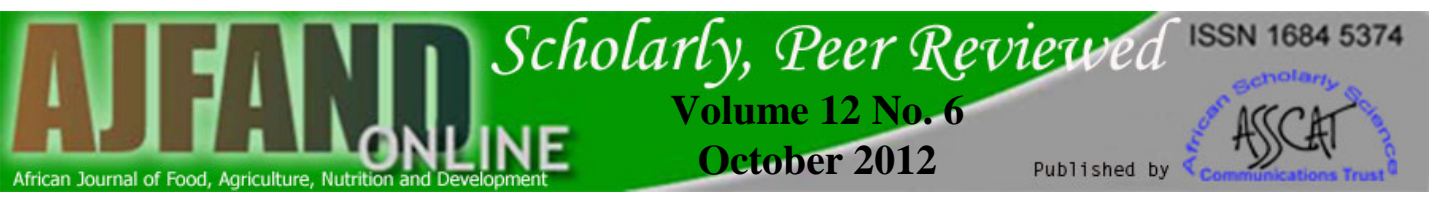

Table 1: Design matrix of the experiment, additive ratio and incubation time interaction

\begin{tabular}{ccccc}
\hline S/N & $\begin{array}{c}\text { Coded } \\
\text { A }\end{array}$ & $\begin{array}{c}\text { Actual } \\
\text { A }\end{array}$ & $\begin{array}{c}\text { Coded } \\
\text { B }\end{array}$ & $\begin{array}{c}\text { Actual } \\
\text { B }\end{array}$ \\
& pepper:tomato & pepper:tomato & Incubation time (hr) & Incubation time (hr) \\
\hline 1 & -1 & $3: 2$ & -1 & 1.5 \\
2 & -1 & $3: 2$ & 1 & 4.5 \\
3 & 1 & $2: 3$ & -1 & 1.5 \\
4 & 1 & $2: 3$ & 1 & 4.5 \\
5 & 1.414 & $0: 5$ & 0 & 3 \\
6 & -1.414 & $5: 0$ & 0 & 3 \\
7 & 0 & $2.5: 2.5$ & 1.414 & 6 \\
8 & 0 & $2.5: 2.5$ & -1.414 & 1 \\
9 & 0 & $2.5: 2.5$ & 0 & 3 \\
10 & 0 & $2.5: 2.5$ & 0 & 3 \\
11 & 0 & $2.5: 2.5$ & 0 & 3 \\
12 & 0 & $2.5: 2.5$ & 0 & 3 \\
13 & 0 & $2.5: 2.5$ & 0 & \\
\hline
\end{tabular}




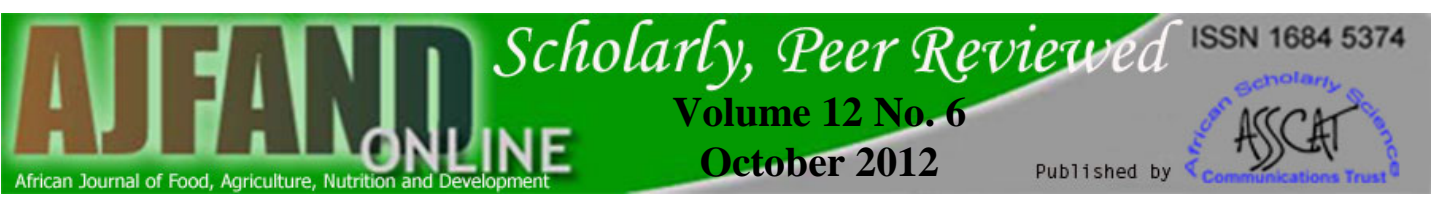

Table 2: Some physical and chemical properties of sweet pepper, tomato and peanut $^{1}$

\begin{tabular}{llll}
\hline Properties & Pepper & Tomato & Peanut \\
\hline Unit Mass (g) & $9.06 \pm 1.02$ & $42.45 \pm 2.15$ & $1.0 \pm 0.00$ \\
Colour (A) & $0.68 \pm 0.01$ & $0.40 \pm 0.01$ & $0.31 \pm 0.01$ \\
Specific Gravity & $0.73 \pm 0.01$ & $0.97 \pm 0.00$ & $0.86 \pm 0.01$ \\
Moisture Content (\%wb) & $88.50 \pm 4.20$ & $91.61 \pm 3.40$ & $7.75 \pm 1.04$ \\
pH & $4.85 \pm 0.74$ & $4.60 \pm 0.91$ & $5.80 \pm 1.04$ \\
Fat (\%) & $0.20 \pm 0.00$ & $0.23 \pm 0.00$ & $44.70 \pm 7.10$ \\
Titratable Acidity (\%) & $0.51 \pm 0.00$ & $0.68 \pm 0.01$ & $2.10 \pm 1.01$ \\
Fiber (\%) & $1.42 \pm 0.01$ & $0.71 \pm 0.00$ & $1.14 \pm 0.02$ \\
Protein (\%) & $1.16 \pm 0.01$ & $0.83 \pm 0.01$ & $22.07 \pm 2.46$ \\
Carbohydrate (\%) & $7.56 \pm 1.77$ & $5.71 \pm 1.93$ & $24.34 \pm 3.33$ \\
\hline
\end{tabular}

${ }^{1}$ All the values are mean of three determinations. 


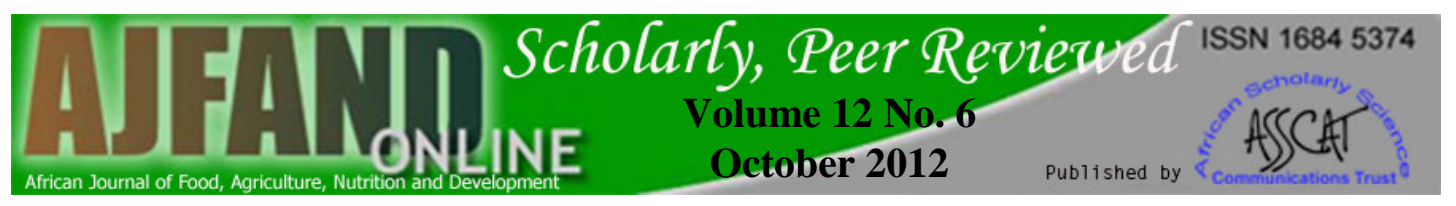

Table 3: Recorded values of responses as influenced by variables ${ }^{2}$

\begin{tabular}{cccccccccc}
\hline $\mathbf{S} / \mathbf{N}$ & $\mathbf{I V}$ & $\mathbf{P V}$ & $\mathbf{F F A}$ & $\mathbf{S V}$ & $\mathbf{C L}$ & $\mathbf{V s}$ & $\boldsymbol{\beta}$-caro & $\mathbf{V i t} \mathbf{E}$ & $\mathbf{V i t ~ K}$ \\
& $\mathbf{( W i j s )}$ & $\mathbf{m e q k g}^{-1}$ & $\mathbf{( \% )}$ & $\mathbf{m g K O H} / \mathbf{g}$ & $\mathbf{( A )}$ & $\mathbf{N s m}^{-2}$ & $\mathbf{\mu g} / \mathbf{1 0 0 g}$ & $\boldsymbol{\mu g} / \mathbf{1 0 0 g}$ & $\mathbf{\mu g} / \mathbf{1 0 0 g}$ \\
\hline 1 & 101.45 & 9.07 & 1.41 & 140.25 & 0.19 & 0.01 & 755.00 & 12.30 & 8.61 \\
2 & 101.37 & 9.10 & 1.41 & 140.25 & 0.20 & 0.02 & 751.00 & 13.60 & 8.40 \\
3 & 116.90 & 11.90 & 4.82 & 180.50 & 0.13 & 0.02 & 690.00 & 12.00 & 7.54 \\
4 & 101.41 & 9.01 & 1.41 & 140.25 & 0.16 & 0.02 & 760.00 & 13.70 & 7.10 \\
5 & 108.83 & 9.53 & 1.97 & 196.35 & 0.16 & 0.02 & 740.00 & 12.80 & 6.90 \\
6 & 100.07 & 5.45 & 0.85 & 184.15 & 0.18 & 0.02 & 800.00 & 14.60 & 6.75 \\
7 & 108.83 & 12.50 & 1.97 & 196.35 & 0.20 & 0.19 & 697.00 & 13.50 & 7.40 \\
8 & 108.83 & 9.00 & 1.41 & 140.25 & 0.17 & 0.01 & 725.00 & 12.60 & 7.60 \\
9 & 101.14 & 10.70 & 3.14 & 168.30 & 0.14 & 0.01 & 857.00 & 11.90 & 8.60 \\
10 & 103.21 & 11.07 & 3.14 & 168.10 & 0.13 & 0.02 & 861.00 & 12.10 & 7.90 \\
11 & 107.69 & 10.03 & 2.94 & 169.00 & 0.13 & 0.01 & 867.00 & 12.60 & 8.50 \\
12 & 105.57 & 11.16 & 3.18 & 167.70 & 0.13 & 0.02 & 859.00 & 11.80 & 8.20 \\
13 & 104.79 & 10.41 & 3.01 & 166.30 & 0.14 & 0.01 & 860.00 & 12.30 & 8.10 \\
C & 103.38 & 3.66 & 0.56 & 56.10 & 0.13 & 0.01 & 525.00 & 6.70 & 5.30 \\
\hline
\end{tabular}

Where $\mathrm{C}$ is without any treatment (control), IV is iodine value, PV is peroxide value,

FFA is free fatty acid, SV is saponification value, CL is colour, $\beta$-caro is beta carotene

Vit $\mathrm{E}$ is vitamin $\mathrm{E}$ and Vit $\mathrm{K}$ is vitamin $\mathrm{K}$.

${ }^{2}$ All the values are mean of three replicates. 


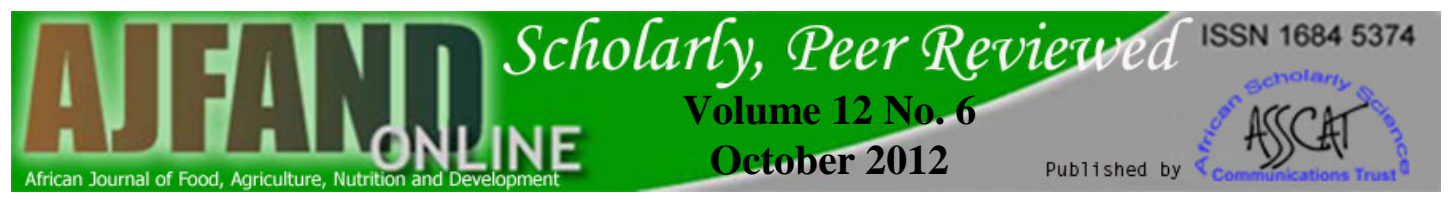

\section{REFERENCES}

1. CGIAR. Research and Impact: Areas of Research: Groundnut. Consultative Group on International Agricultural Research (CGIAR) Available online: http://www.cgiar.org/impact/research/groundnut.html, Accessed 14th May 2009.

2. ICRISAT. Groundnut (peanut). International Crops Research Institute for the Semi-Arid Tropics, Available online: http://www.icrisat.org/Groundnut/Groundnut.htm, Accessed 14th May 2009.

3. Pohs KH and $\mathbf{K}$ Machell The manual screw press for small-scale extraction, Intermediate Technology Publications Ltd. Rome, Italy, 1995.

4. Anyasor GN, Ogunwenmo KO, Oyelana OA, Ajayi D and J Dangana Chemical analyses of groundnut (Arachis hypogaea) oil. Pakistan J Nut., 2009; 8: 269-272.

5. Weiss EA Oil Seed Crop. $2^{\text {nd }}$ Edition Blackwell Longman Group Ltd. USA, 2000.

6. Codex Codex Alementarius Commission: Fats, Oils and Related Product, Vol 18. FAO/WHO Food Standard Programme ALINORM, 2008.

7. Hanif R, Iqbal Z, Iqbal $\mathbf{M}$, Hanif $\mathbf{S}$ and $\mathbf{M}$ Rasheed Use of vegetables as nutritional food: role in human health. J Agric. Bio. Sci., 2006; 1: 18-22.

8. Bafidu GIO, Akapapunam MA and VN Mybemere Fate of $\beta$-carotene in processed leaves of fluted pumpkin (Telfaria occidentalis), a popular vegetable in Nigerian diet. Plant Foods for Human Nut., 1995; 48: 141-147.

9. Montgomery DC Design and Analysis of Experiments: Response surface method and designs. John Wiley and Sons, Inc. New Jersey, USA, 2005.

10. ASABE. Moisture measurement-peanut. American Society of Agricultural and Biological Engineers. (ASAE S410.1 Dec. 1982 R 2008), 679-680, 2008.

11. Afoakwa EO, Budu AS and AB Merson Application of response surface methodology for optimizing the pre-processing conditions of bambara groundnut (Voandzei Subterranea) during canning. Int. J Food Eng., 2007; 2:1-21

12. AOAC. Official Methods of Analysis, $18^{\text {th }}$ ed. Association of Official Analytical Chemists; Gaithersburg, MD, USA, 2005.

13. Codex. Recommended Methods of Analysis and Sampling. Codex Stan 1999; 2007. 


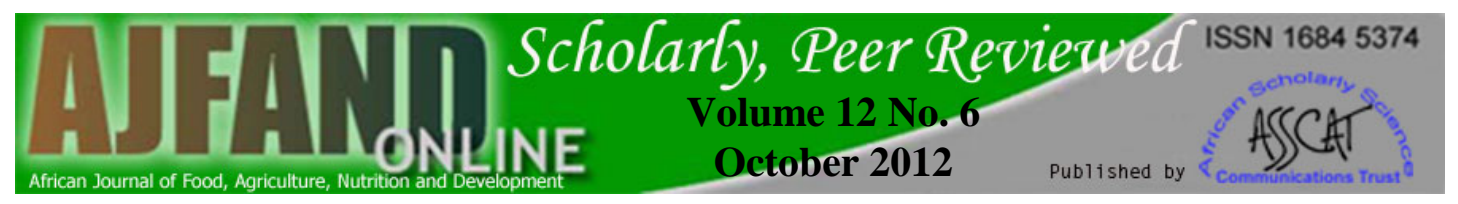

14. McClements DJ Analysis of carbohydrates. http://wwwnix.oit.umass.edu/ mcclemen/. Accessed January 9, 2010.

15. AOCS. The Official Methods and Recommended Practices of the American Oil Chemists' Society, $19975^{\text {th }}$ Edi. Champaign IL: American Oil Chemists Society, 1997.

16. Matsushita $\mathbf{S}$ Peroxide Value Determining Test for Oils and Fats www.FreePatents Online.com, 1978. Accessed 2nd October, 2009.

17. Pearson DA The Chemical Analysis of Food (8th ed.), J.A. Churchill, London, 1981.

18. McWaters KH and JP Cherry Emulsification, foaming and protein solubility properties of defatted soybean, peanut, field pea and pecan flours. J Food Sci., 1977; 42: 1444-1447.

19. Walsh KB Commercial adoption of technologies for fruit grading with emphasis on NIRS. Information and Technology for sustainable Fruit and Vegetable Production, 2005; 5: 399-408.

20. Adedeji O, Taiw KA, Akanbi CT and R Ajani Physicochemical properties of four tomato cultivars grown in Nigeria. J Food Proc Pres. 2006; 30: 79-86.

21. FDA. Department of Health and Human Services. 21 CFR 114.990. http://www.cfsan.fda.gov/;2003. Accessed 8 November, 2009.

22. Ganjloo A, Abdul Rahman R, Osman A, Bakar J and M Bimak Kinetics of crude peroxidase inactivation and colour changes of thermally treated seedless guava (Psidium guajava L.). Food Bioprocess Technolo, 2011; 8: 1442-1449.

23. Ghodsvali A, Haddad KM and LL Diosady Aqueous extraction of virgin olive oil using industrial enzymes, 18th 385 National Congress on Food Technology, Hashhad, I. R, Iran, 2008.

24. Albashir M Effect of gamma irradiation on fungal load, chemical and sensory characteristics of walnut. Stored Products Res, 2004; 40: 355-362.

25. Ranalli A, Malfatti A, Pollastri L, Contento S and L Lucera Analytical quality and genuineness of enzyme-extracted virgin olive oil. J Food Quality, 2003; 26: 149- 164.

26. Hui YH Edible Oil and Fat Products Processing Technology. In Bailey's Industrial Oil and Fat Products, Vol. 4. John Wiley and Son's Inc. New York, 1996. 


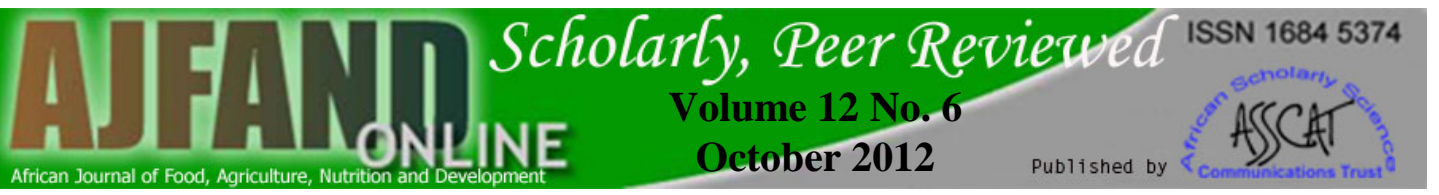

27. O' Brien RD Fats and Oils, Formulating and Processing for Applications. Technical Publishing, Company Inc. Lancaster USA, 1998.

28. Gayathri GN, Platel K, Prakash $\mathbf{J}$ and $\mathbf{K}$ Srinivasan Influence of antioxidant spices on the retention of $\beta$-carotene in vegetables during domestic cooking processes. Food Chem, 2004; 84: 35-43.

29. Pokorný J, Parkányiová L, Réblová Z, Trojáková L, Sakurai H, Uematsu T, Miyahara $\mathbf{M}$ and T Yano. Changes on storage of peanut oils containing high levels of tocopherols and $\beta$-carotene. Czech J Food Science, 2003; 21: 19-27. 